\title{
Evaluate the Therapeutic Effect of Allicin (L-cysteine) on Clinical Presentation and Prognosis in Patients with COVID-19
}

\author{
Hosein Yaghoubian (1), Hossein Niktale (2), Arash Peivandi Yazdi (3), Vahideh \\ Ghorani (4), Masoud Mahdavi Rashed (5), Amir Masoud Hashemian (6)
}

(1) Department of Emergency Medicine, Mashhad University of Medical Sciences, Mashhad, Iran; (2) Innovation, Technology and Entrepreneurship, Molecule of allicin (L-cysteine) with Stabilized Oxidation Capacity, Mashhad, Iran; (3) Lung Diseases Research Center, Mashhad University of Medical Sciences, Mashhad, Iran; (4) Clinical Research Unit, Faculty of Medicine, Mashhad University of Medical Sciences, Mashhad, Iran; (5) Akbar Children Hospital, Mashhad University of Medical Sciences, Mashhad, Iran; (6) Department of Emergency Medicine, Faculty of Medicine, Mashhad University of Medical Sciences, Mashhad, Iran.

This article is distributed under the terms of the Creative Commons Attribution Noncommercial License (CC BY-NC 4.0) which permits any noncommercial use, distribution, and reproduction in any medium, provided the original author(s) and source are credited.

\begin{abstract}
The antiviral effectiveness of allicin (L-cysteine) has been shown by numerous studies in both levels of clinical and animals. The aim of this study was to evaluate the therapeutic effect of allicin (L-cysteine) on clinical presentation and prognosis. In the current study, 66 patients with COVID-19 based on clinical, radiological presentations and RT-PCR results, were enrolled in two groups of placebo and allicin. In the both allicin (L-cysteine) and placebo groups ( $\mathrm{n}=33$ in each group), the capsules were prescribed two times a day for two weeks. Clinical signs and symptoms, blood parameters and chest CT scan were evaluated before and two weeks after treatment. The results showed that allicin (L-cysteine) could significantly impact on improvement of signs and symptoms of COVID-19 after two weeks of treatment in comparison to placebo. Allicin (L-cysteine) not only improve the clinical signs, but also ameliorate the lab and radiological data, which suggest a therapeutic effect for this agent in COVID-19. Our data suggest the therapeutic effect of allicin (L-cysteine) on COVID-19 through improvement of clinical symptoms and acceleration of the healing process.
\end{abstract}

Key Words: COVID-19; Allicin; chest CT; laboratory findings; clinical trial.

Eur J Transl Myol 31 (2): 9518, 2021 doi: 10.4081/ejtm.2021.9518

Two identified zoonotic coronaviruses, severe acute respiratory coronavirus syndrome (SARS-CoV) and Middle East respiratory coronavirus syndrome (MERS$\mathrm{CoV}$ ) have been reported to have disturbed the respiratory tract and caused significant outbreaks in two past decades. ${ }^{1,2}$ Severe acute respiratory syndrome coronavirus 2 is a recently identified coronavirus, first discovered in Wuhan, China, in December 2019. The disease was formally named coronavirus disease 2019 (COVID-19) on 11 February 2020. ${ }^{3}$ Epidemiological results have effectively determined the path of person-toperson dissemination in COVID-19, which has expanded exponentially and has become a global public health issue. ${ }^{4,5}$ Many patients have acquired pneumonia, which can worsen quickly as a result of respiratory failure. Elderly and patients with poor immune function have higher susceptibility and mortality rates. ${ }^{6-8}$ It has been well documented that most patients typically have pneumonia with irregular chest computed tomography (CT) scan results. Popular signs at onset include fever, cough, and myalgia or tiredness. ${ }^{9}$ A significant number of patients suffered serious complications, including acute respiratory distress syndrome (ARDS); 32\% of patients required intensive care (ICU) admission; and $15 \%$ died. According to the latest studies, the mortality rate for severe cases was $60.5 \% .{ }^{10-12}$ Unfortunately, the pathogenesis of COVID-19 is uncertain and there is no appropriate treatment.

Allicin, a bioactive ingredient of garlic, has been reported to possess antiviral activity in vivo in the case of common cold, and it could reduce the growth of influenza virus and $\mathrm{H} 1 \mathrm{~N} 1$ in vitro. $^{13,14}$ Many reports have shown phytochemicals as inhibitors of key protease in coronavirus by using molecular modeling approaches. ${ }^{15}$ In this regard, the effectiveness of allicin (L-cysteine) on COVID-19 has been reported recently in vitro. ${ }^{16}$ However, no clinical effectiveness study has reported. So, we aimed to use the allicin (L-cysteine) to evaluate the therapeutic effect of this agent on clinical presentation and prognosis. 


\section{Materials and Methods}

\section{Research design}

In this randomized double-blinded clinical trial, 83 patients were enrolled with COVID-19 according to the diagnosis by the emergency medicine specialist and the approval of the infectious disease specialist and based on RT-PCR results, referred to Emergency Department of Imam Reza Hospital, Mashhad.

Patients were selected based on following inclusion and exclusion criteria:

1. Inclusion criteria: Patients diagnosed with COVID19 based on the patients' clinical, radiological findings and RT-PCR results; age between 18-70 years; absence of pregnancy or lactation;

2. Exclusion criteria: History of allergies to allicin, garlic or onions; patient with a history of hypotension or gastrointestinal bleeding; low blood pressure at the beginning of the study; immunodeficient patients; chemotherapy; organ and bone marrow transplantation, and patients with autoimmune diseases; patient who require ventilation

In this study, 83 patients were randomly and equally allocated to allicin (L-cysteine) $(90 \mathrm{mg} / \mathrm{kg}$ ) or placebo groups.

However, 66 patients completed the treatment period. In the allicin (L-cysteine) and placebo groups ( $\mathrm{n}=33$ in each group), the capsules were prescribed three times a day for two weeks (every 8 hours). The molecule of allicin (Lcysteine) with stable oxidation capacity by a new allotropic process is one of the active ingredients in organosulfur as the main composition of this supplement. In order to blinding the results, allicin (L-cysteine) and placebo capsules with similar appearance were prepared and given to the patients by a nurse or a physician. It should be noted that both groups were treated with routine treatment of COVID-19 based on the latest regional guidelines. Patients in allicin (L-cysteine) group were treated with routine treatment plus allicin (Lcysteine) $90 \mathrm{mg} / \mathrm{kg}$, and placebo groups were treated with routine treatment plus placebo capsules. Evaluation of clinical symptoms and vital signs (cough, dyspnea, myalgia, anosmia, chill, consciousness, diarrhea, headache, nasal congestion, nausea and vomiting, sore throat, weakness, taste disorder, respiratory rate, pulse rate, temperature, $\mathrm{O} 2$ saturation), blood parameters (total and differential white blood cells, red blood cells, hemoglobin, platelet, C-reactive protein) and chest CT scan were performed pretreatment and two weeks after treatment. This study was performed in accordance with the principles of the Declaration of Helsinki and was approved by Mashhad University of Medical Sciences (Code \# Ir.mums.rec.1399.289Iran). Written informed consent was obtained from all patients.

\section{Statistical analysis}

The data was described by frequency [percentage (\%)] or mean \pm S.D. Comparisons within each group were performed using McNemar and Wilcoxon Tests and the comparison between the two groups was tested by MannWhitney U test and $\kappa 2$ test. All statistical analysis was implemented in SPSS 25.0, p values $<0.05$ were considered statistically significant.

\section{Results}

In this study, 33 patients in placebo group (66.7\% men and $33.3 \%$ women) and 33 patients in allicin (L-cysteine) group $(72.7 \%$ men and $27.3 \%$ women) were included. The average age of patients in placebo and allicin (Lcysteine) groups was $(52.9 \pm 5.0)$ and $(51.4 \pm 5.1)$ years, respectively. There were no differences in these values between groups. Demographic characteristics of the subjects are displayed in Table 1.

The most common symptom in both placebo and allicin (L-cysteine) groups was dyspnea $(77.8 \%$ and $75.8 \%$, respectively); and the most uncommon symptom was diarrhea in both groups ( $3 \%$ in both groups). At the beginning of study, there was no significant changes in clinical symptoms between two groups. However, frequency of anosmia and nasal congestion in allicin (Lcysteine) group were significantly higher than placebo group ( $\mathrm{P}=0.031$ and $\mathrm{P}=0.009$, respectively). At the end of the study, allicin (L-cysteine) led to a significant decrease of cough, dyspnea and myalgia in treated patients compared to placebo group $(\mathrm{p}<0.05$ to $\mathrm{p}<0.01)$,

Table 1. Demographic characteristics of patients.

\begin{tabular}{lcccc}
\hline \multirow{2}{*}{ Variables } & \multicolumn{3}{c}{ Groups } & \multirow{2}{*}{ P-value } \\
\cline { 3 - 5 } & Male & Placebo & Allicin & \\
Sex (\%) & $\mathbf{6 6 . 7 \%}$ & $72.2 \%$ & $\mathbf{0 . 6 1 8}^{*}$ \\
& Female & $33.3 \%$ & $27.3 \%$ & \\
\hline Age (Mean \pm SD) & & $\mathbf{3 9 . 2 \pm 8 . 4 0}$ & $\mathbf{3 8 . 9 7 \pm 8 . 3 7}$ & $\mathbf{0 . 9 0 3}^{* *}$ \\
\hline $\begin{array}{l}* \text { Chi-Square test } \\
* * \text { T-independent sample test }\end{array}$ & & & \\
\end{tabular}


Effect of Allicin (L-cysteine) on COVID-19

Eur J Transl Myol 31 (2): 9518, 2021 doi: 10.4081/ejtm.2021.9518

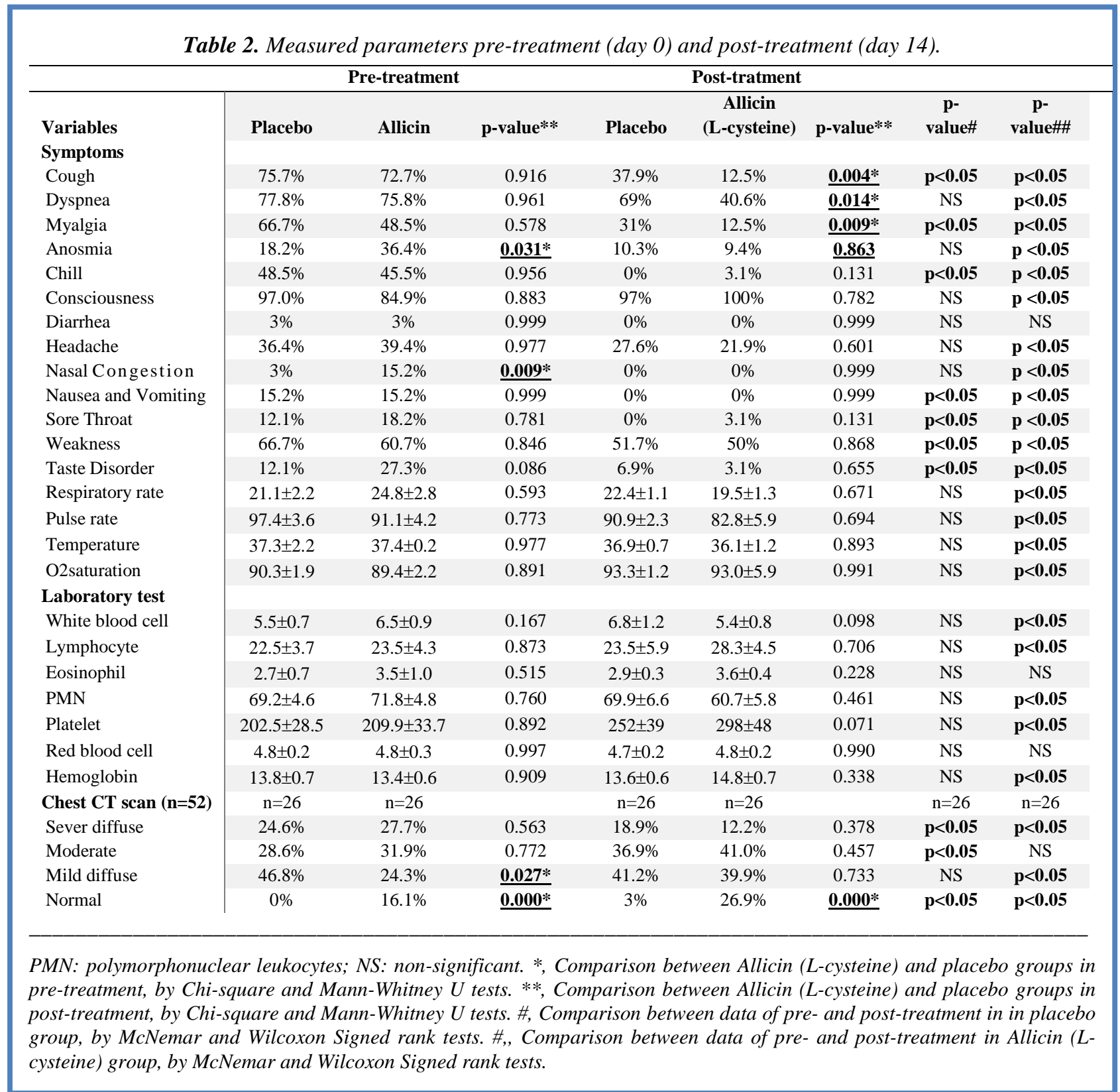

(Table 2). Significant statistical different did not show in blood parameters between groups in both pre- and posttreatment (Table 2). In this study, the results of chest CT scan categorized to four levels including normal, mild, moderate, and severe based on the lung involvement in chest CT scan. Before treatment, the number of patients with normal and mild chest CT scan were significantly different between two groups ( $\mathrm{p}<0.05$ to $\mathrm{p}<0.001$ ). However, there was a significant increase rate of normal chest CT scan in allicin (L-cysteine) group compared to placebo group after two weeks of treatment ( $p<0.001$, Table 2). In addition, Figure 1 illustrated the chest CT scan study in some patients before and after treatment. The results showed the significant improvements of lung based on lesions distribution and involvement of various regions of lungs as well as CT score. Comparison of the measured parameters before and after the intervention showed that in placebo group, all parameters (except cough, myalgia, chill, nausea and vomiting, sore throat, weakness, and taste disorder, as well as chest CT) were not significantly changed after two weeks treatment compared to baseline values. However, lots of symptoms except diarrhea and blood parameters as well as chest CT scan were improved after treatment compared to before treatment in the allicin (L-cysteine) group ( $\mathrm{p}<0.05$ for all cases) (see Table 1).

\section{Discussion}

In this study, we showed that allicin (L-cysteine) could significantly improve clinical symptoms of COVID-19 after two weeks of treatment in comparison to placebo. Allicin (L-cysteine) not only improve the clinical signs, 

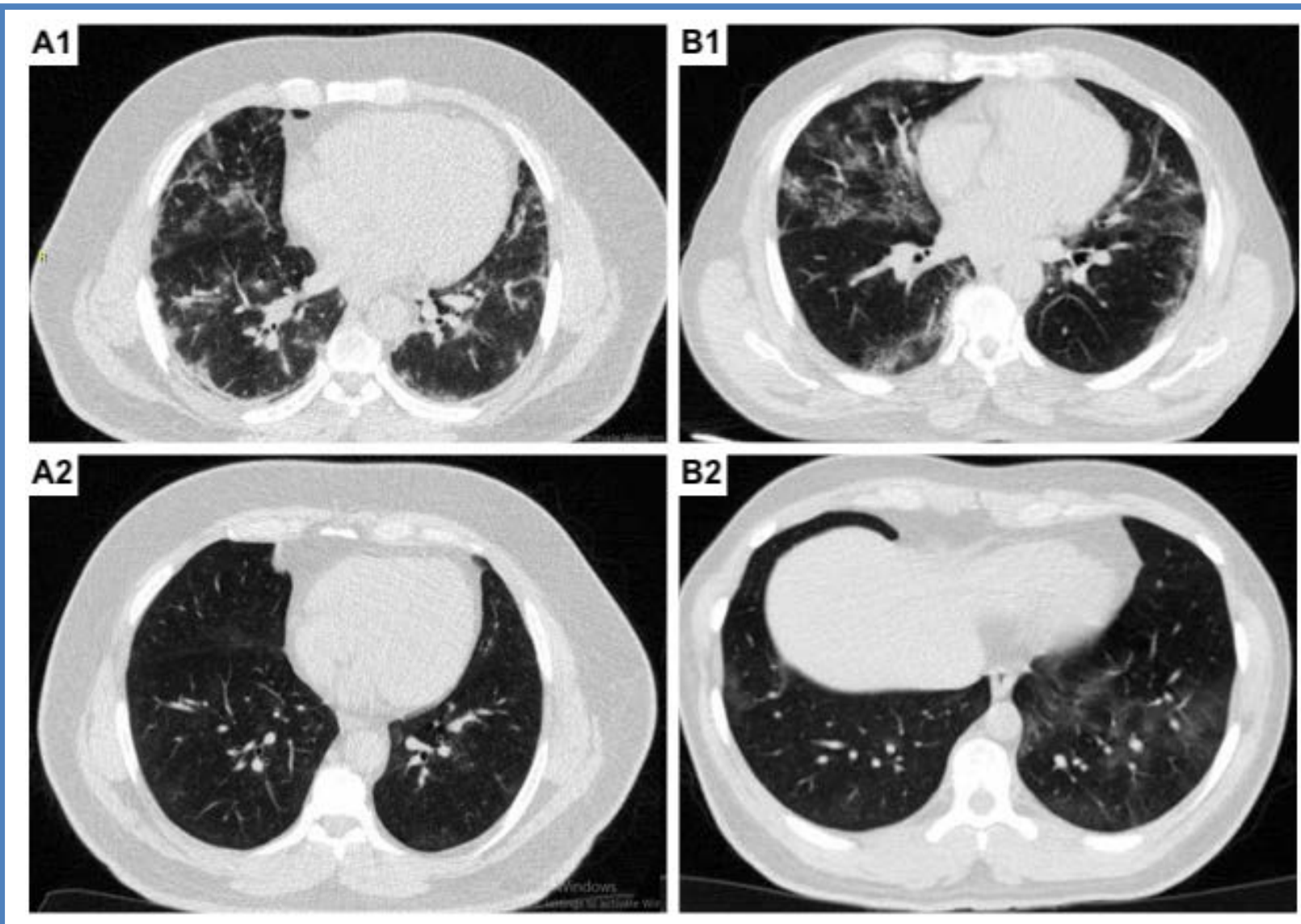

Fig 1. The results of chest $C T$ scan before (A1 and B1) in comparison to after treatment (A2 and B2) with allicin. A1 and A2 illustrated a 65-years old man with dyspnea and fever with the chest CT severity score of 12 initially, which improve to 4 after treating with allicin. B1 and B2 illustrated 71-years old man with shortness of breath and fever with the chest CT severity score of 10 initially, which improve to 4 after treating with allicin

but also ameliorate the lab and radiological data, which suggest a therapeutic effect for this agent in COVID-19. Plants and their extracts have been used to treat human diseases since ancient times. ${ }^{17}$ Previous experiments have shown that phytochemicals are good therapeutic agents for the treatment of various diseases, including viral pathogens, either by blocking the virus from penetrating host cells or by attacking viral proteins in host cells. ${ }^{18}$ Inhibition of proteolytic action of viral proteases has been studied in the production of various antiviral drugs such as atazanavir, lopinavir, nelfinavir, ritonavir and saquinavir. ${ }^{19}$ Protease inhibitory potentials have been found to exist in the extracts of cloves $A$. sativum and rhizomes of $C$. longa, and Z. officinale. ${ }^{20}$ Allicin, curcumin and gingerol have been listed by the Phytochemical and Ethnobotanical Databases as the key phytochemicals in cloves A. sativum and rhizomes of $C$. longa, and $Z$. officinale. ${ }^{20}$ Compounds have been retrieved from the PubChem database in ligand file format (SDF). Plants have been known as a good source of protease inhibitors. ${ }^{21}$ However, in addition to their antiviral potential, a detailed examination of the pharmacokinetics and bioavailability of the described compounds was required to ensure protection. Recent reports have suggested that these phytocompounds could be valuable for the development of drugs useful for the prevention of coronavirus entry and replication. ${ }^{21}$ Although, the effectiveness of allicin (L-cysteine) has been evaluated in vitro, no clinical study has been conducted to evaluate this issue. In this regard, this study is the first to evaluate the effectiveness of this drug on COVID-19.

In the current study, we observed that allicin (L-cysteine) was effective in improvement of both clinical and laboratory parameters in patients with COVID-19. The results indicated that allicin (L-cysteine) could improve the chest involvement based on the radiological findings. Although, some signs and symptoms might be reified during the two weeks, but allicin (L-cysteine) could accelerate this process. In addition, since the toxicity and hyperallergic reaction to allicin (L-cysteine) have not been reported yet, this drug might be a novel treatment in clinical settings. 
In conclusion, we showed that allicin (L-cysteine) could significantly improve and accelerate the healing process within two weeks of treatment. Allicin (L-cysteine) not only improve signs and symptoms of COVID-19, but also could induce high impact on both laboratory and radiological findings.

\section{List of acronyms}

OA - osteoarthritis

TKA - total knee arthroplasty

SPPB - Short Physical Performance Battery

6MWT - Six-Minute Walk test

\section{Authors contributions}

HY, SE, HN, APY, VGH, MMR, and AMH conceived and designed the experiments, performed the data analyses and wrote the paper. All authors have read and approved the manuscript.

\section{Availability of data and materials}

The datasets used and/or analysed during the current study are available from the corresponding author on reasonable request.

\section{Acknowledgments}

This research is the result of a student thesis of Mashhad University of Medical Sciences. Authors thank Saeideh Ebrahimpour for her help in this study

\section{Funding}

None.

\section{Conflict of Interest}

The author declares no competing interests.

\section{Ethical Publication Statement}

We confirm that we have read the Journal's position on the issues involved in ethical publication and affirm that this report is consistent with those guidelines.

\section{Corresponding Author}

Amir Masoud Hashemian, Department of Emergency Medicine, Faculty of Medicine, Mashhad University of Medical Sciences, Mashhad, Iran. Phone: 00989124244517. ORCID iD: 0000-0001-5668-6599 Email: HashemianAM11@gmail.com

\section{E-mails and ORCID iD of Coauthors}

Hosein Yaghoubian: YaghoubianH1@mums.ac.ir ORCID iD: 0000-0002-1110-9939

Hossein Niktale: hoseen.nikta@gmail.com ORCID iD: 0000-0002-5345-196X

Arash Peivandi Yazdi: peivandia@mums.ac.ir ORCID iD: 0000-0002-8274-6783

Vahideh Ghorani: GhoraniSV@mums.ac.ir ORCID iD: 0000-0001-6883-7972

Masoud Mahdavi Rashed: MahdaviRM@mums.ac.ir ORCID iD: 0000-0003-4594-9095

\section{References}

1. Wang C, Horby PW, Hayden FG, Gao GF. A novel coronavirus outbreak of global health concern. Lancet. 2020 Feb 15;395(10223):470-473. doi: 10.1016/S0140-6736(20)30185-9. Epub 2020 Jan 24. Erratum in: Lancet. 2020 Jan 29.

2. Bhimraj A, Morgan RL, Shumaker AH, Lavergne V, Baden L, Cheng VC, et al. Infectious Diseases Society of America Guidelines on the Treatment and Management of Patients with COVID-19. Clinical infectious diseases: an official publication of the Infectious Diseases Society of America. 2020.

3. Wang D, Hu B, Hu C, Zhu F, Liu X, Zhang J, Wang B, Xiang H, Cheng Z, Xiong Y, Zhao Y, Li Y, Wang X, Peng Z. Clinical Characteristics of 138 Hospitalized Patients With 2019 Novel Coronavirus-Infected Pneumonia in Wuhan, China. JAMA. 2020 Mar 17;323(11):1061-1069. doi: 10.1001/jama.2020.1585. Erratum in: JAMA. 2021 Mar 16;325(11):1113.

4. Oso BJ, Adeoye AO, Olaoye IF. Pharmacoinformatics and hypothetical studies on allicin, curcumin, and gingerol as potential candidates against COVID-19-associated proteases. J Biomol Struct Dyn. 2020 Sep 2:1-12. doi: 10.1080/07391102.2020.1813630. Epub ahead of print.

5. CDC COVID-19 Response Team. Severe Outcomes Among Patients with Coronavirus Disease 2019 (COVID-19) - United States, February 12-March 16, 2020. MMWR Morb Mortal Wkly Rep. 2020 Mar 27;69(12):343-346. doi: 10.15585/mmwr.mm6912e2.

6. Mehta P, McAuley DF, Brown M, Sanchez E, Tattersall RS, Manson JJ; HLH Across Speciality Collaboration, UK. COVID-19: consider cytokine storm syndromes and immunosuppression. Lancet. 2020 Mar 28;395(10229):1033-1034. doi: 10.1016/S0140-6736(20)30628-0. Epub 2020 Mar 16.

7. Nishiura H, Oshitani H, Kobayashi T, Saito T, Sunagawa T, Matsui T, Wakita T, COVID M, Suzuki M. Closed environments facilitate secondary transmission of coronavirus disease 2019 (COVID-19). MedRxiv. 2020 Jan 1.

8. Bai Y, Yao L, Wei T, Tian F, Jin DY, Chen L, Wang M. Presumed Asymptomatic Carrier Transmission of COVID-19. JAMA. 2020 Apr 14;323(14):14061407. doi: 10.1001/jama.2020.2565.

9. Cucinotta D, Vanelli M. WHO Declares COVID-19 a Pandemic. Acta Biomed. 2020 Mar 19;91(1):157160. doi: 10.23750/abm.v91i1.9397.

10. Tahir Ul Qamar M, Alqahtani SM, Alamri MA, Chen LL. Structural basis of SARS-CoV-2 3CLpro and anti-COVID-19 drug discovery from medicinal plants. J Pharm Anal. 2020 Aug;10(4):313-319. doi: 10.1016/j.jpha.2020.03.009. Epub 2020 Mar 26. 
11. Middleton J, Reintjes R, Lopes H. Meat plants-a new front line in the covid-19 pandemic. BMJ. 2020 Jul 9;370:m2716. doi: 10.1136/bmj.m2716.

12. Shree P, Mishra P, Selvaraj C, Singh SK, Chaube R, Garg N, Tripathi YB. Targeting COVID-19 (SARS-CoV-2) main protease through active phytochemicals of ayurvedic medicinal plants Withania somnifera (Ashwagandha), Tinospora cordifolia (Giloy) and Ocimum sanctum (Tulsi) - a molecular docking study. J Biomol Struct Dyn. 2020 Aug 27:1-14. doi: 10.1080/07391102.2020.1810778. Epub ahead of print.

13. Khanal P, Duyu T, Patil BM, Dey YN, Pasha I, Wanjari M, Gurav SS, Maity A. Network pharmacology of AYUSH recommended immuneboosting medicinal plants against COVID-19. J Ayurveda Integr Med. 2020 Nov 25. doi: 10.1016/j.jaim.2020.11.004. Epub ahead of print.

14. D'Adamo I, Gastaldi M, Morone P. The post COVID-19 green recovery in practice: Assessing the profitability of a policy proposal on residential photovoltaic plants. Energy Policy. 2020 Dec;147:111910. doi: 10.1016/j.enpol.2020.111910. Epub 2020 Sep 23.

15. Monajjemi M, Mollaamin F, Shojaei S. An overview on Coronaviruses family from past to Covid-19: Introduce some inhibitors as antiviruses from Gillan's plants. Biointerface Research in Applied Chemistry. 2020 Jan 1;10(3).

16. Khaerunnisa S, Kurniawan H, Awaluddin R, Suhartati S, Soetjipto S. Potential inhibitor of
COVID-19 main protease (Mpro) from several medicinal plant compounds by molecular docking study. Prepr. doi10. 2020 Mar 13;20944:1-4.

17. Khaerunnisa S, Kurniawan H, Awaluddin R, Suhartati S, Soetjipto S. Potential inhibitor of COVID-19 main protease (Mpro) from several medicinal plant compounds by molecular docking study. Prepr. doi10. 2020 Mar 13;20944:1-4.

18. Shekh S, Reddy KK, Gowd KH. In silico allicin (Lcysteine) induced S-thioallylation of SARS-CoV-2 main protease. Journal of Sulfur Chemistry. 2020 Sep 16:1-2.

19. Khaerunnisa S, Kurniawan H, Awaluddin R, Suhartati S, Soetjipto S. Potential inhibitor of COVID-19 main protease (Mpro) from several medicinal plant compounds by molecular docking study. Prepr. doi10. 2020 Mar 13;20944:1-4.

20. Boone HA, Medunjanin D, Sijerčić A. Review on Potential of Phytotherapeutics in Fight against COVID-19. Int J Innov Sci Res Technol. 2020;5:481-91.

21. Fasogbon BM, Ademuyiwa OH, Bamidele OP, Wahab IE, Ola-Adedoyin AT, Alakija O. Positive Therapeutic Role of Selected Foods and Plant on Ailments with a Trend Towards COVID-19: A Review. Prev Nutr Food Sci. 2021 Mar 31;26(1):111. doi: 10.3746/pnf.2021.26.1.1.

Submitted: November 19, 2021

Revision received: April 18, 2021 Accepted for publication: April 18, 2021 